\title{
LA ASIMETRÍA, QUE NO LOS HECHOS DIFERENCIALES, COMO NOTA DISTINTIVA DEL ESTADO AUTONÓMICO
}

JOSÉ TUDELA ARANDA 
SUMARIO

1. LAS DIALÉCTICAS EN TORNO A LA SIMETRÍA COMO ELEMENTO DEFINITORIO DEL ESTADO AUTONÓMICO. 2. LOS TÉRMINOS DEL DEBATE EN LA CONSTITUCIÓN. A. Las asimetrías políticas. B. Los hechos diferenciales. 3. FRUSTRACIÓN, REBELIÓN Y EMULACIÓN. 4. NACIONALIDAD ES CUALQUIERA Y LA NECESIDAD DE VOLVER A LOS ORÍGENES. A. La Declaración de Barcelona y sus reflejos estatutarios. B. Los Estatutos de autonomía de segunda generación y la apariencia de emulación. 5. UN BALANCE QUE SE PROYECTA AL FUTURO 


\title{
LA ASIMETRÍA, QUE NO LOS HECHOS DIFERENCIALES, COMO NOTA DISTINTIVA DEL ESTADO AUTONÓMICO
}

\author{
JOSÉ TUDELA ARANDA ${ }^{1}$ \\ Letrado de las Cortes de Aragón \\ Profesor Titular (acreditado) de Derecho Constitucional
}

\section{LAS DIALÉCTICAS EN TORNO A LA SIMETRÍA COMO ELEMENTO DEFINITORIO DEL ESTADO AUTONÓMICO}

La opción por un modelo de Estado políticamente descentralizado conlleva la asunción de determinadas dialécticas que son inherentes a esta forma de organización política del poder. La primera, consustancial e inevitable, es la que enfrenta a la unidad con la autonomía. La segunda, menos generalizable, es la que enfrenta simetría con asimetría. En todo caso, las dos van a responder a una misma idea/necesidad. La de integrar la diversidad en la unidad política que representa el Estado (Watts, 2006: 135, 171).

La primera, la relación entre unidad y autonomía, como se ha dicho, está implícita en cualquier modelo de descentralización política, sea cual sea su intensidad. Desde el momento en que se abre la puerta de la descentralización, esa tensión formará parte estructural del diseño del Estado. Así, no puede entenderse que la misma llegue a ser definitoria del modelo territorial español. No, al menos, en sus rasgos esenciales. Con todo, podrían extraerse rasgos diferenciales suficientemente significativos como para considerar que influyen en la definición del modelo y en su singularización. Rasgos que tienen una naturaleza básicamente procedimental al encontrarse ligados a la forma de acceso y profundización a la autonomía (Aja, 2014: 31-66). Características importantes para describir nuestro modelo territorial, pero insuficientes para singularizarlo.

${ }^{1}$ Letrado de las Cortes de Aragón. Palacio de la Aljafería. 50004 Zaragoza. Email: jtudela@cortesaragon.es 
Para encontrar esas notas constitutivas de nuestro modelo de Estado, es preciso acudir a la segunda de las dialécticas mencionadas, a la que enfrenta un modelo simétrico con un modelo asimétrico. Será este extremo el que se desarrolle en las páginas que siguen. Su vocación es poner de manifiesto como esta tensión no sólo es determinante para, en su momento, haber optado por un modelo territorial descentralizado políticamente, y como tal, una decisión anterior a la propia Constitución, sino el factor clave para entender la evolución del Estado autonómico, incluyendo su deriva contemporánea (Fossas y Requejo, 1999; Tornos, 2015: 169).

Como se ha indicado, se trata de una dialéctica estrictamente preconstitucional. Más. Puede decirse que es una de las fuentes ideológicas a las que habrá de dirigirse el constituyente para adoptar una de las decisiones políticas fundamentales del nuevo orden político (Castella, 2016: 78). La convicción de que la relación de los distintos territorios con el autogobierno era muy diversa y, en consecuencia, exigía respuestas diferentes se sentía como algo tan natural como un accidente más del paisaje. Los precedentes históricos; la pluralidad lingüística; o la existencia de partidos nacionalistas, algunos casi centenarios, eran sólo algunos datos para cimentar esta convicción. La necesidad de establecer un sistema de autogobierno era la respuesta que se debía dar a las reclamaciones de un número limitado de territorios, básicamente País Vasco y Cataluña, para resolver la eterna cuestión territorial (Gordillo et al, 2017; 183-206). Una cuestión que el nacionalismo no podía dar por resuelta mediante un modelo de descentralización homogénea, un modelo federal clásico (Carreras, 2014: 18).

Ideología. Sí. La convicción de que el autogobierno se relacionaba sólo con unos territorios que reunían determinadas características, no se limitaba a un posible principio inspirador de carácter procedimental. Se trataba de una premisa ideológica que debía inspirar toda la construcción del Estado autonómico y su ulterior evolución. Porque la idea que subyacía no era una idea de cantidad, más o menos autogobierno, sino de cualidad. De cualidad constitucional de los territorios afectados. Naciones frente a regiones. Y al margen de las que serían evidentes diferencias en el quantum de la autonomía, la cualidad de nación otorgaba a esos territorios un estar diferente en el Estado. Diferencias que, básicamente, deberían traducirse en reconocimiento identitario y bilateralidad, al margen de otras, «menores», de orden competencial y de financiación que se pudiesen establecer. Si bien este postulado ideológico era básicamente el de los nacionalistas, lo cierto es que, con los matices de intensidad que se deseen, sobre todo en lo referente a la cualidad de los distintos territorios, todas las formaciones políticas entendían que, en relación con el autogobierno, unos territorios eran diferentes a otros y, más, que había profundas razones históricas, políticas, culturales, que explicaban su singularidad. Así, el modelo inicial era un Estado similar al regional italiano, con autonomías de muy distinta cualidad (Montilla, 2016: 44)

Antes de continuar, resulta preciso realizar dos reflexiones preliminares. La primera, hace referencia a la relación entre federalismo y asimetría o, más exactamente, entre descentralización y asimetría. Una cuestión que suele debatirse desde la premisa de que el canon federal implica unión de iguales. Sin embargo, la reali- 
dad, en su inagotable capacidad para imponerse a ideales políticos y jurídicos, acabó quebrando la regla general y ofreciendo ejemplos de Estados federales asimétricos y, más, de asimetrías en la práctica totalidad de Estados descentralizados (Watts, 2006: 171-180; Blanco Valdés, 2012: 219-238; Castella, 2016: 72-75). Algo que no sólo no puede extrañar, sino que es coherente con la misma lógica de una ideología que, ante todo, pretende dar cabida a la diversidad en la unidad. Y, por definición, esa diversidad podrá ser heterogénea y necesitar de respuestas heterogéneas (Tajadura, 2016: 69).

Creo que resulta preciso detenerse en este extremo por la relevancia que esta premisa tiene para el actual debate constitucional español. No se trata de imponer a la realidad un modelo ideal. Se trata de subsumir una realidad en las premisas teóricas de que disponemos. Aunque ello conlleve en ocasiones quebrar no ya posibles modelos ideales, sino, incluso, personales convicciones políticas e ideológicas. Precisamente, éste será uno de los grandes valores del federalismo, si no su gran valor. Su flexibilidad para posibilitar estas soluciones (Tajadura y De Miguel, 2014: 42). La complejidad de la realidad territorial de la España contemporánea es indiscutible. La idea de que sólo desde presupuestos de una notable cuantitativa y cualitativa descentralización es posible dar respuesta al reto que plantea, tampoco parece que pueda ser discutido (Solozábal, 2014: 21). Como no lo puede ser que desde la teoría constitucional sólo el federalismo ampara respuestas a esas exigencias. Que las mismas sean asimétricas no excluyen la solución federal. Más bien, no hay otra opción que el federalismo y lo que habrá que saber es construir un rostro federal para un modelo que, como todos, ofrece singularidades específicas.

La segunda reflexión preliminar que es preciso realizar, tiene un alcance conceptual. Se refiere a la relación entre asimetría y hechos diferenciales. Inmediatamente, habrá ocasión de detenerse en este concepto. Ahora, como punto de partida es preciso subrayar que los hechos diferenciales no implican ni son asimetría. Una distinción esencial para la finalidad de este trabajo ${ }^{2}$. Ha sido relativamente habitual calificar el Estado autonómico como asimétrico sobre la base de la existencia de estos hechos diferenciales (Aja, 2014: 324-367; López Aguilar, 1997: 25-74). Es una afirmación razonable en cuanto, literalmente, un hecho diferencial siempre conlleva asimetría. Pero que oculta una acepción estricta del término. La asimetría es el fruto de una decisión política que puede o no adoptarse (Watts, 2006: 171). El hecho diferencial es una diferencia, valga la redundancia, consecuencia de la existencia de un hecho objetivo como la lengua, los derechos históricos, la existencia de un derecho foral propio o la insularidad. Lógicamente, en sentido laxo del término, la existencia de cualquiera de estas circunstancias implica una asimetría. Y, también, lógicamente,

2 Se trata de una distinción compleja para la que pueden encontrase múltiples referencias. Es clásica la diferencia entre asimetrías políticas y asimetrías constitucionales (Watts, 2006: 171-175). Sobre la confusión de las lógicas diversas de la asimetría y los hechos diferenciales (Trujillo, 2005: 35-54). Como señaló García Roca, las mismas diferencias en la enunciación de los hechos diferenciales, son muestra de la confusión existente al respecto. 
su existencia, en especial algunas particularmente potentes políticamente, como la lengua o los derechos históricos, pueden ser motivo, o uno de los motivos, que explique finalmente la opción por una asimetría política. Pero, a pesar de su evidente relación, son conceptos diferentes y es útil no asimilarlos. Puede coincidirse en que el foco sobre los hechos diferenciales ha acabado diluyendo el significado de la asimetría en nuestro modelo territorial (Castella, 2016: 81).

Básicamente, por asimetría debe entenderse una diferente forma de estar en el Estado. Es decir, un reconocimiento singular con el consiguiente régimen de relaciones y competencias que se traduce en una posición cualitativamente diferente en el conjunto del Estado. Como todo en el federalismo, un régimen graduable que podrá abarcar desde la integración en la adopción de las decisiones del Estado a las relaciones financieras; desde el régimen competencial a una diferente organización institucional. Siempre, singular. Siempre, diferente al estatus de otros territorios. Y diferente no por la existencia de determinadas circunstancias objetivas no generalizables, sino por la existencia de una decisión política consciente. Decisión que, lógicamente, debe ser fruto del acuerdo del todo y, así, una decisión con reflejo constitucional.

\section{LOS TÉRMINOS DEL DEBATE EN LA CONSTITUCIÓN}

\section{A. Las asimetrías políticas}

Como se ha indicado, la reflexión sobre la asimetría fue anterior a la Constitución. En verdad, más que anterior, fue un presupuesto. Dos fueron los condicionantes de la decisión final del constituyente. Por un lado, el carácter histórico de la reivindicación de autogobierno en dos territorios, País Vasco y Cataluña, y su íntima conexión con los denominados problemas esenciales de nuestra construcción nacional. Todas las sensibilidades políticas eran conscientes de que sólo un modelo territorial que satisficiese la voluntad de autogobierno de nacionalistas vascos y catalanes, podría asegurar no ya el éxito de ese diseño, sino del propio proyecto político que se abría paso.

Junto a lo anterior, ligado estrictamente a una cuestión política como puede ser una distinta sensibilidad ciudadana en relación con el autogobierno, una circunstancia histórica emergía con relevancia tanto para la definición de la dialéctica estudiada como para el diseño del Estado en su conjunto. Los territorios históricos vascos y Navarra ponían encima de la mesa el precedente de un régimen singular, encubierto bajo la bandera y denominación de derechos históricos. Más. Dos de esos territorios, Álava y Navarra, habían llegado a conservar esa singularidad constitucional incluso durante la dictadura franquista. En el momento de abordar la opción por la descentralización, era inevitable que, al menos, en relación con esos territorios, la decisión final fuese condicionada por la existencia de esos precedentes y se llegase a constitu- 
cionalizar los denominados derechos históricos (Corcuera, 1985: 55-90; Solozábal, 2004: 93-101). Curiosamente, cuando hoy se define el Estado autonómico, la referencia a su carácter simétrico o asimétrico, se repara poco, y casi siempre relativizando su importancia, en el estatus de País Vasco y Navarra. El debate se plantea de forma casi universal alrededor de las restantes Comunidades Autónomas, como si el hecho foral fuese extra constitucional.

Junto a ello, y para completar el mapa relacionado con la asimetría, cabe mencionar no sólo ya las diferencias existentes en relación con el deseo de autonomía política, sino la propia convicción en la identidad territorial. En efecto. Las diferencias no se limitaban a la voluntad de autogobierno. Afectaban también a la propia conciencia de existencia. Al respecto, el mapa resultante era diverso del que podía trazarse en relación con la voluntad de autogobierno en una perspectiva nacionalista. Si éste podía limitarse a País Vasco y Cataluña, el mapa de la identidad histórica y política se extendía, aunque sin llegar a cubrir la totalidad del espacio nacional. Si territorios como Aragón, Galicia, Valencia, Andalucía, Navarra, Asturias, o los dos insulares, tenían una representación inmediata en el colectivo imaginario, con las consecuencias evidentes sobre el proceso que habría de convertirlos en sujetos políticos, otros se encontraban en situación bien diferente. En algunos casos, como el supuesto paradigmático de Castilla, por indefinición respecto de su extensión territorial. En otros, por la debilidad de los precedentes relativos a su sustantividad política.

De este dato se deriva una circunstancia que será de importancia para el desarrollo del Estado autonómico. Frente a la simplificación de un dualismo que enfrenta al Estado con dos Comunidades Autónomas nacionalistas, con clara vocación de autogobierno y un resto del territorio uniforme en cuanto a sus sensibilidades sobre este extremo, la realidad es que la diversidad es, también, la nota que caracteriza a ese «resto». Y una diversidad cualitativa que en ocasiones implica diferencias políticas de gran calado. Una circunstancia que ya estuvo presente en esos meses preconstitucionales en los que fue posible apreciar que, lejos de cualquier atisbo de uniformidad, había una verdadera escala de sensibilidades en relación con el autogobierno (Muñoz Machado, 2007: 134-153).

Por todo ello, puede afirmarse que el constituyente se encontraba condicionado desde presupuestos favorables a la asimetría. La sensibilidad general era que, claramente, no todos los territorios tenían la misma relación con el autogobierno y que esa diferencia debería tener reflejo jurídico constitucional. La Constitución debía establecer las premisas necesarias para dotar a los territorios históricamente sensibles de un notable autogobierno que contribuyese a cerrar una de las grandes cuestiones nacionales. Se entendía que sin su aquiescencia, el modelo territorial que se diseñase, incluso el propio modelo constitucional, nacería muerto. Así, el modelo diseñado por el constituyente será esencialmente abierto, permitiendo hacer realidad la reivindicación nacionalista de autodisposición sobre elementos esenciales (Muñoz Machado, 2014: 99-101). Frente al modelo del anteproyecto constitucional, proceso descentra- 
lizador homogéneo, se definía un modelo basado en la heterogeneidad. No se deseaba, al menos en un primer momento, un modelo de autonomía política, en sentido federal, generalizado (Blanco Valdés, 2014: 179).

Un presupuesto ideológico que tuvo un reflejo contundente en el artículo segundo de la Constitución que distinguiría el reconocimiento de la autonomía a nacionalidades y regiones (Solozábal, 2008: 58-64). Y si bien no llegaba a determinar cuáles eran esas nacionalidades, no dejaba de ser ésta una operación sencilla al sí singularizar aquellos territorios a los que se garantizaba una verdadera autonomía política (Disposición Transitoria Segunda y artículos 151 y 152 de la Constitución). Porque no puede dejar de repararse en el hecho de que la diferencia entre nacionalidades y regiones no era para el constituyente una mera diferencia de procedimiento, de acceso más o menos rápido a lo que se denominaría autonomía plena. La verdadera diferencia era la garantía de la autonomía política. Una garantía que se entendía desde el reconocimiento cualitativo de un hecho nacional al que correspondía naturalmente esa autonomía política. Ese era el significado de una voz, nacionalidad. Garantía de la autonomía al modo del federalismo clásico (Tajadura y de Miguel, 2014: 41). Una voz que, evidentemente, había que leer en contraposición al término región. Las nacionalidades tenían garantizada la autonomía política, artículos 151 y 152 de la Constitución; las regiones, no.

Nacionalidades y regiones. Transcurridos cuarenta años desde la aprobación de la Constitución, y visto los desafíos contemporáneos a los que se tiene que enfrentar la organización territorial, creo que es posible afirmar que esta afirmación del artículo segundo de la Constitución fue uno de sus hallazgos más lúcidos y, simultáneamente, ha sido uno de sus grandes fracasos. Hallazgo en el texto constitucional y fracaso por el desarrollo que del mismo se ha hecho. No advertir el profundo valor político de esa distinción, acabaría provocando su frivolización y, con ella, no sólo la pérdida de valor de las palabras, sino de buena parte del sustrato del acuerdo político del que eran expresión.

No hay que adelantar acontecimientos. La lectura del texto constitucional aún depara significativas enseñanzas. Necesariamente, la distinción del artículo segundo tenía que tener reflejo en el mismo (Fossas, 1999: 275). Como se ha indicado, la esencia de la traducción del citado binomio fue garantizar a las nacionalidades una auténtica autonomía política. Es decir, la capacidad de desarrollar políticas públicas propias mediante la aprobación de leyes, con el correspondiente marco financiero y organización institucional, sobre un elenco significativo de competencias. Autonomía que no se garantizaba a las regiones. Un hecho que, por si sólo, marcaba una diferencia cualitativa entre unos y otros territorios. Junto a ello, se habilitaba un procedimiento que permitía el acceso a esa autonomía en un plazo extraordinariamente breve. Era preciso hacer realidad de manera inmediata una de las decisiones esenciales del nuevo orden político.

La importancia de este régimen jurídico se ha matizado por el hecho de que, simultáneamente, la Constitución prevé la posibilidad de que otros territorios se 
constituyan en Comunidades Autónomas, incluso de que accedan a un régimen similar de autonomía en un tiempo relativamente breve. La objeción es impecable. Existía esa posibilidad y así sucedió. Pero creo que ello no impide afirmar que la concepción ideológica del Estado en la Constitución es asimétrica y que, precisamente, en el hecho de que en su desarrollo se apartase de esta premisa se encuentran una parte de los problemas actuales del Estado. Una desviación ajena al trazado de los principales actores políticos y que, como habrá de verse, se encontrará ligada a distintas coyunturas políticas. Y una desviación que acabará corrigiéndose para retornar a la senda inicial.

Dos hechos vendrían a reforzar esta afirmación. Por un lado, los pactos autonómicos como reflejo del modelo de Estado que se tenía (Muñoz Machado, 2007: 177180). Unos pactos que, lejos de pensar en una situación coyuntural, buscaron traducir con vocación de, al menos, cierta permanencia, la organización del Estado sobre esas bases asimétricas. Recuérdese que en ellos se diferenció claramente entre nacionalidades y regiones, anudándose a unas y a otras regímenes muy distintos. Junto a otras circunstancias evidentes como las diferencias competenciales, cabe llamar la atención sobre el peculiar régimen de limitaciones institucionales que se planteó para las Comunidades Autónomas que accedían a la autonomía por el artículo $143^{3}$.

Una premisa ideológica que se reforzaría incluso cuando, transcurridos los cinco años establecidos en el artículo 148, las Comunidades que habían accedido por el procedimiento previsto en el artículo 143, forzaron una ampliación de su marco competencial. Es preciso insistir en la importancia de lo sucedido en estos años 19921994 (Tudela, 2016: 63-88). Las Comunidades Autónomas se habían asentado. Las estructuras institucionales se habían creado y se ejercían las competencias correspondientes. Si la Constitución fijaba un plazo de cinco años, la solicitud de mejora competencial se había retrasado otros cinco años. Parecía el momento para decidir definitivamente sobre si el modelo territorial iba a ser simétrico o asimétrico. Y, como habrá de verse, y aunque hoy casi siempre se olvide, se decidió que fuese asimétrico. Todavía era la única opción que se percibía como razonable. Es un dato fundamental para comprender la evolución del Estado autonómico. Es casi una lectura universal (Carreras, 2014: 23; Solozábal, 2004: 201), señalar que el proceso de homogeneización, incluso de federalización del Estado, trae cuenta de los pactos de 1992 y el consiguiente proceso de reformas. Es, precisamente, al contrario. Ese proceso tuvo la finalidad de consagrar el Estado asimétrico. Si ese no fue el resultado, se debió, como se verá inmediatamente a la conjunción del azar político con las demandas, precisa-

3 En mi opinión, no se ha llegado a dar suficiente relevancia a estos aspectos institucionales. Con claridad, suponían una rebaja sustancial de la cualidad política de las citadas Comunidades Autónomas. Si bien la rebelión de Aragón y Canarias de 1996 propició que el núcleo de esas limitaciones desapareciese de los Estatutos, aún permanecerían algunas diferencias de gran relevancia política, como la forma de tramitar los Estatutos o los límites a la disolución del correspondiente Parlamento autonómico y posterior convocatoria de elecciones. 
mente insatisfechas por la profunda asimetría resultante de los acuerdos de 1992, de algunas Comunidades.

Junto a lo anterior, la segunda circunstancia que, lógicamente, apuntala la visión asimétrica que de la organización territorial tenía el constituyente, es la constitucionalización de los llamados Derechos históricos y la consiguiente garantía de los muy singulares regímenes jurídico constitucionales anexos a los mismos. Creo que lo evidente en ocasiones solapa el valor que puede implicar una decisión determinada. La constitucionalización de los Derechos históricos y, con ellos, del hecho foral, tenía por si misma la capacidad de definir el Estado como asimétrico y, desde esa definición, introducir un polo de tensión permanente (Laporta, 2006: 9-86). Tensión que, como sucede tantas veces, se va a distanciar de su origen, de manera que no se repare en dónde se encuentra una de las fuentes que alimenta el conflicto.

Pero si es difícil negar que el reconocimiento constitucional de los Derechos históricos y las consecuencias ligadas a los mismos durante el desarrollo constitucional, van a ser una fuente de tensión proporcional a las diferencias, sino privilegios, que directamente van a amparar, y aunque sea a costa de adelantar alguna conclusión, creo que no es vano reparar como, cuarenta años después, en los territorios en los que se garantizó constitucionalmente la singularidad y, por ende, la asimetría, existe comodidad esencial en su inserción en el Estado. Una comodidad que es inevitable oponer a lo sucedido en Cataluña, cuya singularidad además de no ser reconocida constitucionalmente, quedó diluida con el desarrollo constitucional.

\section{B. Los hechos diferenciales}

Como se señaló, cuestión diferente son los denominados hechos diferenciales, expresión felizmente acuñada para denominar las diferencias objetivas entre las distintas Comunidades Autónomas. Más problemático ha sido el uso de la expresión para aludir a diferencias, como por ejemplo competenciales, que son ya el fruto de una decisión política (Aja, 2014: 353-356).

En tanto que circunstancias objetivas, el margen del constituyente era, en este punto, más reducido. La lengua propia, la insularidad, el Derecho foral, los Derechos históricos, ciertas instituciones, estaban allí. Aunque, por supuesto, siempre cabía una opción radical, no anudar consecuencias jurídico-políticas a estas circunstancias, no era ese el clima con el que se enfrentaba la redacción de la Constitución. Al contrario. La premisa era el reconocimiento de la diversidad en la más amplia acepción de la palabra. Personalmente, entiendo que de las circunstancias mencionadas, sólo los Derechos históricos y, en mucha menor medida, el régimen fiscal especial para Canarias, se acercan al espacio de la asimetría 4 .

${ }^{4}$ En el caso del régimen fiscal canario, la distancia respecto de la península y del propio espacio europeo, justifica que se pueda considerar ésta como un hecho objetivo que exige de una respuesta singular. 
Junto a los citados, como se dijo, también se han mencionado como hechos diferenciales otras circunstancias sobrevenidas con plaza en unas Comunidades y en otras, no. Entre los más destacados, algunas diferencias competenciales como la existencia de una policía propia o la gestión de las prisiones; o como ciertas decisiones relativas a instituciones, como el procedimiento de tramitación y aprobación del Estatuto o la disolución anticipada del Parlamento. En mi opinión, estos casos no son hechos diferenciales en sentido estricto. Más bien, se trataría de una manifestación de asimetría, asimetrías estructurales, si se desea matizar (Castella, 2016: 82-83). Es una diferencia importante. La creación de un cuerpo de policía propio se puede extender o no a todas las Comunidades Autónomas. La insularidad, o la existencia de un Derecho foral, no. En la decisión de crear la policía, o de formalizar cualquier otra diferencia, se expresa una voluntad de singularización que es el rasgo distintivo de la asimetría. Y algunos de los citados, como el procedimiento de aprobación de los Estatutos o las condiciones de disolución del Parlamento, poseen gran relevancia política (Balaguer, 1992: 146).

Los hechos diferenciales reflejan diversidad y, desde ésta, algunas diferencias que pueden ser sustantivas. Desde luego, la existencia de una lengua o Derecho foral no son cuestiones menores a la hora de describir el autogobierno de un territorio. Su transcendencia política es evidente. Y desde la misma, se traducen en una estructura que puede leerse como asimétrica y, además, pueden reforzar la vocación asimétrica de un Estado (Allí Aranguren, 2009:154). No en vano, contribuyen a fortalecer la conciencia de singularidad que, en última instancia, fundamenta una voluntad de autogobierno. Pero su propia existencia no permite calificar un Estado como asimétrico. Una prueba concluyente es que su desarrollo y potenciación no ha tenido consecuencias en la caracterización global del Estado. La asimetría responde a un nervio más profundo y esencial. Se trata de determinar la forma de ser y estar en el Estado. Por su relación con el mismo Estado y por su relación con los demás territorios. Así, la asimetría, necesariamente, dependerá de dos perspectivas. De la voluntad de quién aspira a la singularidad y del grado de reconocimiento que a esa voluntad puedan dar los demás. La asimetría se ligará casi necesariamente al conflicto que para el Estado y el federalismo representan la existencia de comunidades con vocación de reconocimiento nacional (Gagnon, 2013: 158-164).

Finalmente, la relación hechos diferenciales/asimetría, debe ser contemplada desde el conjunto. Los hechos diferenciales se dan por supuestos. Como tales, se alejan de la polémica, al menos sobre su existencia. Cuestión diferente puede ser, desde luego, las consecuencias que se les anuden. Por el contrario, la asimetría debe ser una decisión política consciente. Una decisión que, por definición, implica la aceptación de una singularidad por el conjunto. Es por ello que es posible sostener que si bien los hechos diferenciales pueden ayudar a caracterizar una forma de Estado descentralizado, no acabarán por definirlo. La decisión sobre si voluntariamente se incorporan rasgos distintivos para determinados territorios, por el contrario, sí resulta definidora de una estructura territorial. Lo que en estas páginas se sostiene es que el nacimiento y evolución del Estado autonómico ha estado definida por la voluntad de singula- 
rización de las Comunidades nacionalistas y por la respuesta que esa voluntad ha tenido a lo largo del tiempo. Circunstancias a las que más allá de las dinámicas políticas, daba amparo el ordenamiento constitucional.

\section{FRUSTRACIÓN, REBELIÓN Y EMULACIÓN}

Como se ha señalado, la división constitucional entre territorios con «conciencia política» y «voluntad de autogobierno» y el resto, fue realizada con anclajes que, al menos, deben calificarse como débiles. Para objetivar la singularidad e inmediatez del régimen singular de País Vasco y Cataluña, no se encontró otra fórmula que aludir al pasado, en concreto a la aprobación de la autonomía por referéndum durante la Segunda República. Circunstancia que era atribuible, en principio, a Cataluña, País Vasco y Galicia (Blanco Valdés, 2014: 114-227). Así, se encontraba la llave para la autonomía inmediata de País Vasco y Cataluña, y se sumaba a Galicia, otro territorio con una identidad cultural definida. Operación perfecta. Las nacionalidades se distinguían desde el origen. La asimetría como principio rector de la nueva organización territorial quedaba consagrada. No importaba que el hecho utilizado para delimitar los territorios con condición de nacionalidad fuese algo tan endeble como un referéndum que, salvo en el caso de Cataluña, fue realizado en plena guerra y sin consecuencias políticas en lo referente a un efectivo autogobierno. No importaba que otros muchos territorios tuviesen tan avanzados como País Vasco y Galicia su proceso de autonomía durante la Segunda República. Lo importante era alcanzar el objetivo de singularizar los territorios en los que el nacionalismo era fuerza política relevante y hacerlo desde el inicio de la andadura constitucional (Castella, 2016: 78-79). Desde el nacionalismo, la asimetría era la respuesta necesaria a una nación de naciones (Requejo, 2001: 110-132)

El anudar el acceso a la autonomía por el procedimiento del artículo 151 e, implícitamente, la condición de nacionalidad a un hecho del pasado, provocó que, inmediatamente, hiciese fortuna la denominación Comunidades históricas para aludir a los citados territorios. Frente a ellos, el resto. Un conjunto de regiones, ¿Sin historia? Relacionar una determinada posición constitucional a la historia en un País como España, no era una buena idea; denominar a unas con el calificativo de históricas y privar del mismo a otras, era aún peor. La denominación hacía visible una discriminación objetiva ya que no había razón alguna que justificase calificar, o, al menos, circunscribir, la calificación de históricas a sólo los tres territorios mencionados. La historia en política, más en un País como España, es un arma que carga el diablo. La historia podía ser título suficiente para sostener un distinto régimen de autogobierno.

Desde luego, esa denominación no era cuestión sustantiva. Pero sí daba forma a lo que para muchos era una discriminación injustificable. La existencia de diferencias a favor de unos territorios que bien podían verse como privilegios. No haber hecho la necesaria pedagogía sobre esas diferencias y haberlas amparado en una vaga referencia 
histórica, sólo podía ser acicate para la disconformidad. La mecha de la rebelión y de la emulación, que de las dos cosas habría que hablar, estaba abierta. Una semilla particularmente proclive a germinar en aquellos territorios que si bien no podían aducir la tradición nacionalista de País Vasco o Cataluña, o singularidades forales como Navarra, habían demostrado sobradamente una especial sensibilidad hacia el autogobierno, vinculada a factores diversos como la geografía, la cultura y lengua o la historia. O una combinación de estas circunstancias. Eran, entre otros y muy singularmente, los casos de Andalucía, Aragón, Comunidad Valenciana y Canarias (Ruiz Robledo, 1986; Garrido, 1999).

Antes de avanzar en el proceso de rebelión y emulación que conducirá a la perfección del Estado autonómico, hay que indicar que, objetivamente, existían circunstancias suficientes para en el momento de la elaboración de la Constitución, singularizar a País Vasco y Cataluña. Y, de hecho, hay que insistir en que, por más que sea evidente, el País Vasco fue singularizado. En todo caso, lo relevante para nuestro discurso es hacer notar que las circunstancias políticas eran suficientemente diferentes en País Vasco y Cataluña, como para pensar que debería darse a estos territorios una solución singularizada en el conjunto de un Estado descentralizado 5 . Y así lo pensó el constituyente. Pero con vergüenza. Por ello, se añadió a los mismos Galicia y por ello no llegó a explicitarse esa singularidad, al menos para Cataluña. Posiblemente, en esta opción cautelosa radicarán una buena parte de los males futuros. Si bien se aceptaba la premisa, la necesidad de dar una respuesta inmediata a las pretensiones de autogobierno de País Vasco y Cataluña, y hacerlo desde una posición singular respecto al resto de los territorios, se optaba por una fórmula ambigua y equívoca. Si nos trasladamos a aquellos días, es posible que una opción explícita, que incluyese a Cataluña con la variante que se eligiese, hubiese sido aceptada por el todo. No en vano el proceso preautonómico ya había sido sustancialmente diferente en esa Comunidad.

Un apunte especial merece Galicia. Como se habrá observado, es premisa de esta reflexión considerar que la condición constitucional de Galicia como nacionalidad deriva más de una dudosa casualidad histórica que de hechos políticos que justificasen la decisión. Al menos, que la justificasen en relación con otros territorios. Porque en sentido estricto, Galicia pertenecerá a esa categoría de territorios que bien pueden caer bajo la denominación de tercera España, junto con las mencionadas Comunidades de Aragón, Navarra, Valencia o Canarias. Singularidad, sí; identidad nítida, también. Pero la reivindicación política del autogobierno no se desarrollaba en este territorio en términos comparables a lo que sucedía en País Vasco y Cataluña. Y sólo esa relación con el autogobierno podía llegar a justificar el reconocimiento de una verdadera singularidad política, es decir, de una asimetría constitucional.

${ }^{5}$ No sólo la historia política reciente de estos territorios y hechos culturales como la lengua sustentan esta afirmación. Por encima de ellos, se sitúa la fuerza que los partidos políticos nacionalistas tenían como reflejo de una voluntad asentada de autogobierno que, al menos en la misma proporción, no lo estaba en otras regiones de España. 
Así, aprobada la Constitución en diciembre de 1978, con singular celeridad se tramitaron los Estatutos de País Vasco y Cataluña, aprobados de forma simultánea, con fecha de 18 de diciembre de 1979. Tan sólo un año después de la aprobación de la Constitución, Cataluña y País Vasco disponían de la pieza jurídico constitucional esencial para desplegar todas las potencialidades de su autogobierno. Una suerte muy diversa corrió el Estatuto de Galicia, corroborando la idea de que su adición a estos dos territorios había sido más fruto de la casualidad que de la convicción. Fue aprobado el 6 de abril de 1981, después de que durante el iter de su tramitación sufriese distintos avatares, que reflejaban con claridad las diferencias políticas que subyacían en relación con los de Cataluña y País Vasco (Sarmiento, 2003).

De esta manera, se abría paso un mapa que respondía a lo pensado por los constituyentes. Dos Comunidades de primera, a las que habría que adicionar la singularidad de Galicia y Navarra, y un resto por ordenar, con matices en la identidad y reivindicación, pero, a la postre, clara y necesariamente diferenciado de los dos territorios a los que en verdad respondía la apuesta por la autonomía política. El mapa de las dos Españas en el nuevo modelo de descentralización política estaba dibujado. Un mapa naturalmente asimétrico y coherente con las premisas ideológicas predominantes en el momento del debate constitucional. Se respondía así a la doble necesidad de responder a la histórica cuestión planteada por el nacionalismo vasco y catalán y al desafío que suponía encontrar un modelo político administrativo que sirviese de revulsivo para mejores servicios y gestión de la España no nacionalista.

Se había cumplido, y con celeridad, el proyecto constitucional. Pero la asimetría, para tener opciones de efectividad, requiere no sólo de la aquiescencia de quién persigue la posición asimétrica, sino también la conformidad del resto. Como se indicó, nada se hizo para que ésta fuese posible. Si bien en Comunidades como la Valenciana, Aragón o Canarias, los movimientos de rechazo ante esta formulación y de búsqueda de un orden más homogéneo, fueron relevantes, la rebelión que daría inicio al proceso de emulación que caracterizará al Estado autonómico en su primera fase, tuvo como protagonista a Andalucía. Curiosamente, una Comunidad sin lengua propia, sin singularidades geográficas particulares, sin partidos nacionalistas. Un territorio con una identidad indiscutible pero que, objetivamente, no parecía reunir los requisitos para ser candidata a abanderada de la revuelta. No los tenía... pero. Porque si bien es cierto que carecía de las circunstancias antedichas, todas ellas definitorias de reivindicaciones de autogobierno, también lo es que en Andalucía subyacía un fondo de identidad política relevante y, lo más significativo, se trataba del territorio de mayor población gobernado por el partido en la oposición. Por un PSOE que no gobernaba en el Estado y que difícilmente podía aspirar en ese momento a gobernar en Galicia, Cataluña o País Vasco. Si a ello se suma el fermento regalado por un discurso de agravio, es fácil comprender la rapidez con la que la llama de la reivindicación territorial en clave de homologación con los territorios ya llamados históricos, es decir, con aquellos que disponían de autonomía plena, prendió en la ciudadanía andaluza. Andalucía quebraría el diseño del constituyente (Montilla, 2016: 44). 
La consecuencia fue activar el mecanismo previsto en la Constitución para posibilitar el acceso por la vía rápida a esa autonomía plena. Un procedimiento cuya complejidad es una muestra más, y no irrelevante, del diseño asimétrico de la Constitución. La historia es conocida y no es preciso repetirla (Ruiz Robledo, 1986). Sobre el resultado sí es preciso volver, siquiera sea con brevedad. Andalucía se incorpora como nacionalidad a las tres Comunidades que han accedido a la autonomía plena, única que garantiza una verdadera condición política. De esta manera, se quiebra el diseño si no constitucional, sí de los constituyentes. Y, se puede afirmar, de los nacionalistas. El reconocimiento de la autonomía política con todas sus consecuencias no va a ser ya signo distintivo de las Comunidades con preponderancia nacionalista. Dicho de otra manera, se rompe la ecuación nacionalismo/autonomía. Y con ella, algunas notas que con el tiempo se deberían adherir, como un régimen singular de financiación o el discurrir bilateral de las relaciones. La consecuencia última era evidente aunque en ese momento pareciese lejana. Si la autonomía política que la Constitución parecía reservar a unos territorios determinados se abría a todos, habría que encontrar una forma de distinguir a esos territorios en el conjunto de un Estado globalmente descentralizado. Pero aún era una opción minoritaria.

La denominada rebelión andaluza supuso un hecho de naturaleza cuasi constituyente. Al menos, en lo referido a la organización territorial del Estado. El modelo previsto por el constituyente se veía transformado en uno de sus elementos esenciales. La autonomía política no sería sólo la respuesta a la histórica demanda de los nacionalismos vasco y catalán. La autonomía política se extendía como la fórmula política generalizada para todos los territorios que tuviesen voluntad de acceder a la misma. La suma conformaría un modelo generalizado y potente de descentralización política. Es cierto que puede aludirse que ese modelo estaba ya en la propia Constitución. Pero, como se indicó, se trataba, en todo caso, de un modelo subyacente, un modelo sometido a tiempo y condición. De hecho, lo sucedido en Andalucía fue percibido universalmente como un suceso extraordinario, alejado de la normalidad del desarrollo constitucional. El modelo era el que traducía con consecuencias políticas nítidas la distinción entre nacionalidades y regiones del artículo 2, en relación con la DT Segunda y los artículos 151 y 152. Con otras voces, puede decirse que la rebelión andaluza supuso el puente para transitar desde el modelo de Estado regional previsto en la Constitución a un modelo de Estado cuasi federal. El rostro del federalismo que hoy muchos ven en nuestro modelo territorial, no aparece en el texto constitucional. Comenzaría a asomarse tras la aprobación del Estatuto de Autonomía de Andalucía (Carreras, 2014: 23). Mas, es importante, sólo a perfilarse. Aún con la incorporación de Andalucía, el mapa seguía respondiendo a la ideología asimétrica que había dibujado el constituyente. El diseño de la autonomía de las «regiones» estaba por dibujar y todo hacía indicar que no sería similar al de las nacionalidades. Andalucía había abierto camino para la homogeneización del Estado, pero no estaba escrito que ese camino fuese a ser transitado. Más bien, al contrario. Los pactos autonómicos de 1981 consagrarían la construcción asimétrica del constituyente, si bien con la incorporación 
de Andalucía (Muñoz Machado, 2007: 181), tal y como se reflejará en los Estatutos de las restantes Comunidades Autónomas.

Los años posteriores a febrero de 1983, fecha de la aprobación de los últimos Estatutos (Extremadura; Islas Baleares; Madrid y Castilla y León), fueron años de consolidación de la incipiente autonomía. Era preciso aprobar las leyes que debían soportar la estructura institucional básica, e, incluso, encontrar sedes físicas para dar cuerpo a los nuevos entes políticos. Una tarea ingente que fue realizada en un muy corto plazo de tiempo y con un elevado nivel de eficacia. En cualquier caso, el esfuerzo necesario era suficiente para durante un tiempo desviar la atención de la reclamación de un mayor nivel de autonomía. Pero la insatisfacción en algunas Comunidades subyacía. Los términos comparativos no dejaban de utilizarse y la mirada más pronto que tarde volvería a la previsión constitucional prevista en el artículo 148.

Precisamente, este artículo, y muy en particular, la previsión de una ampliación competencial pasado el plazo de cinco años, resulta uno de los más paradójicos de los dedicados por la Constitución a la organización territorial del Estado (Ortego Gil, 2008: 2256-2259). La brevedad del término establecido, cinco años, apenas una legislatura, encierra dos poderosas contradicciones. Por una parte, con la propia dinámica de asunción competencial. Transformar con radicalidad un diseño competencial tan sólo cinco años después de haberse establecido, carece, aparentemente, de todo sentido. Más cuando se piensa que ese diseño exige una reforma estatutaria. Por otra, porque esa brevedad entra en abierta contradicción con el diseño asimétrico que parecía ser la apuesta ideológica del constituyente. De hecho, puede decirse que si la rebelión de Andalucía fue el suceso «revolucionario» que transformó el modelo de Estado previsto por los constituyentes, el plazo de 5 años del artículo 148, fue su caballo de Troya.

De acuerdo con el mismo, era natural que una vez asentados los cimientos institucionales de la autonomía, las Comunidades del artículo 143 de la Constitución, se planteasen una ampliación del techo competencial. Así, en los inicios de la década de los noventa, con Gobierno en el Estado del Partido Socialista, se inició un debate sobre cuáles deberían ser los términos de esa ampliación. En este punto, debe recordarse que si bien la cuestión competencial era protagonista de la discusión, no era la única diferencia con las Comunidades del artículo 151. Como se dijo, estas Comunidades tenían una serie de limitaciones institucionales que fácilmente se podían traducir como la desconfianza ante el ejercicio que un menor pueda hacer de sus facultades. Más allá de lo que en sí mismo podían suponer, esas limitaciones simbolizaban la distinta consideración constitucional que merecían las diferentes Comunidades. Recuérdese que las mismas afectaban a las instituciones básicas, incluyendo al Parlamento, con una drástica limitación de los periodos de sesiones y prohibición de profesionalizar a los Diputados.

De nuevo, es preciso obviar lo que es sobradamente sabido. El debate sobre cómo debía acometerse la eventual ampliación del marco competencial de las Comunidades del artículo 148 finalizó con un pacto entre PSOE y PP por el que se transferían 
algunas competencias relacionadas en el artículo 149 de la Constitución. Si bien el listado competencial es más amplio, tanto en la presencia como en la ausencia, el acuerdo se circunscribía, básicamente, a transferir educación y no hacerlo con sanidad (VV.AA: 1993). Por lo demás, se mantenían las limitaciones institucionales. Un aspecto importante hacía referencia a la técnica. No se procedería a la reforma de los Estatutos, sino que se aprobaría una Ley Orgánica conforme al artículo 150.2 de la Constitución. Una expresión más de la reserva con la que se contemplaba la autonomía de las Comunidades del 143. Éste fue, muy sucintamente el contenido de los denominados «Acuerdos autonómicos» firmados en Madrid el 28 de febrero de 1992 (Muñoz Machado, 1992: 85-105: Aja, 2014: 56-61). Más allá, estos acuerdos perseguían «ultimar... la definición concreta del desarrollo del Título VIII de la Constitución». Éste era el último sentido de los pactos. Cerrar el Estado autonómico. Y hacerlo de manera asimétrica. Los acuerdos de 1992 son los últimos relativos al desarrollo del Estado autonómico que fueron fruto del consenso de los dos grandes partidos nacionales. Su finalidad, cerrar el Estado autonómico; el modelo resultante, como se ha indicado, era claro. Un Estado netamente asimétrico, tanto en lo competencial como en lo institucional. Se era coherente con el diseño del constituyente.

Es importante destacar esta circunstancia que confirma la ideología netamente asimétrica que presidía el Estado autonómico. Si como era el deseo de sus firmantes, el desarrollo territorial se hubiese cerrado en ese año, el mapa de las autonomías hubiese sido un mapa de dos velocidades. Si finalmente derivó hacia una fórmula homogeneizadora, no fue porque esa fuese la voluntad de las dos grandes formaciones políticas de ámbito nacional. Precisamente, lo que aparecía como la consagración de un modelo asimétrico redobló las tensiones en algunos territorios, particularmente en las Comunidades de Canarias y Aragón, ambas gobernadas por partidos nacionalistas. Partidos que hicieron de la equiparación con las Comunidades del 151 la bandera de sus reivindicaciones. El azar de los tiempos políticos hizo el resto. Con posterioridad a la celebración de las elecciones generales de marzo de 1996, el Partido Popular, ganador de las mismas, necesitó del apoyo de los Diputados de Partido Aragonés y de Coalición Canaria. La suma era decisiva para posibilitar la investidura de José María Aznar como Presidente del Gobierno Una condición se impuso al resto. La aprobación de una reforma de los respectivos Estatutos de Autonomía que dotasen a estas Comunidades Autónomas de la misma autonomía que las denominadas históricas. El acuerdo fue inmediato. La condición fue aprobar las reformas antes de finalizar el año. El 30 de diciembre se publicaban los dos textos en el Boletín Oficial del Estado. Las dos Comunidades se reconocían como nacionalidad; se corregían la gran mayoría de las diferencias competenciales todavía existentes, y, muy especialmente, se asumía sanidad; finalmente, se eliminaban las restricciones institucionales que permanecía en los Estatutos. Si bien todavía era posible encontrar alguna diferencia (disolución; tramitación y aprobación de los Estatutos; alguna competencia), esencialmente se podía decir que, finalmente, las dos Comunidades mencionadas lograron la paridad perseguida. Los nuevos Estatutos reconocían un 
nivel de autogobierno similar al de Cataluña y Andalucía. Ahora, sí. El puente hacia un modelo federal ortodoxo que en su día había levantado Andalucía, se transitaba (Carreras, 2014: 24). Saltada la barrera por Aragón y Canarias, era casi obligado extender el nuevo régimen a las restantes Comunidades. La característica racionalizadora del federalismo y las propias exigencias funcionales de la descentralización, actuaron como motores de una inercia que en muchos casos se desarrolló al margen de la correspondiente Comunidad Autónoma (Tajadura y De Miguel, 2014: 34; Solozábal, 2004: 201). El proceso culminó con la reforma del Estatuto de La Rioja en 1999. Pero todo ello tuvo lugar en contradicción clara con lo acordado en los pactos de 1992. De hecho, este proceso de igualación competencial fue la ruptura por el Gobierno del Partido Popular de los pactos de 1992, tal y como se puede observar con claridad en los diarios de sesiones correspondientes a la tramitación de los Estatutos de Aragón y Canarias en las Cortes Generales.

Finalmente, hay que advertir que una diferencia cualitativa premió la iniciativa canaria y aragonesa (Tudela, 2016: 89-94). Sólo estas dos Comunidades asumieron en su texto la condición de nacionalidad. Así, ya eran seis Comunidades las se denominaban en sus Estatutos como nacionalidad. A ellas, había que sumar la singularidad como Comunidad Foral de Navarra. Si la voz nacionalidad, con las consecuencias que la Constitución parecía anudar a la misma, buscaba dar respuesta a la exigencia histórica de reconocimiento singular de Cataluña y País Vasco, la generalización de la voz diluía cualquier posibilidad de éxito.

\section{NACIONALIDAD ES CUALQUIERA Y LA NECESIDAD DE VOLVER A LOS ORÍGENES}

La evolución descrita muestra con nitidez como las tensiones derivadas del binomio simetría/asimetría fueron determinantes tanto para el diseño territorial en la Constitución de 1978 como en su desarrollo posterior. Ahora bien, si en 1994 era ingenuo pensar que podía imponerse un orden homogéneo y asimétrico desde arriba, en 1999 lo era también pensar que un Estado esencialmente homogéneo como resultado final del desarrollo constitucional fuese aceptado sin más por aquellas formaciones nacionalistas que desde antes de la aprobación de la Constitución habían hecho bandera de la singularidad.

\section{A. La Declaración de Barcelona y sus reflejos estatutarios}

No parece que pueda atribuirse a la casualidad que fuese en julio de 1998 cuando las tres principales formaciones políticas de las originariamente denominadas Comunidades históricas, suscribiesen la denominada Declaración de Barcelona (Solozábal, 2004: 199). Su inicio es concluyente tanto en relación con su objetivo como en la identificación de las premisas de las que se partía: «Al cabo de veinte años de demo- 
cracia, continúa sin resolverse la articulación del Estado español como plurinacional. Durante este periodo hemos padecido una falta de reconocimiento jurídico-político e, incluso, de asunción social y cultural de nuestras respectivas realidades nacionales en el ámbito del Estado». La Declaración podía haberse limitado a estas líneas. Veinte años después, el Estado no se había desarrollado como plurinacional. Más. No se reconocían las respectivas realidades nacionales. A la elaboración y firma del manifiesto no se invitó a fuerzas políticas nacionalistas de otros territorios. La propia convocatoria era una demostración más de la vocación netamente asimétrica que del Estado tenían las fuerzas nacionalistas. Porque, no se olvide, su construcción se cimentaba en la existencia de tres naciones que convivían con el resto de territorios del Estado o, simplemente, con Castilla. Las tres que se consideraban no reconocidas, se convocaban en Barcelona.

A la vista de lo sucedido desde entonces, es preciso reparar en la importancia de este texto (Unzueta, 1999). También, en la ausencia de la sensibilidad política necesaria para medir su significado y estudiar las respuestas necesarias. Igualmente, también puede denunciarse que faltó sensibilidad jurídica para responder a otras carencias denunciadas desde una perspectiva más técnica (Aja y Viver, 2003). Junto a ello, desde luego, es, sería, preciso realizar una lectura crítica de su contenido. Partir como premisa del vacío, de veinte años de un casi no hacer en relación con el reconocimiento de la diversidad cultural y territorial, simplemente, era absurdo, sino malintencionado. Reclamar más cuantitativa y cualitativamente sólo podía hacerse con legitimidad desde la premisa del profundo reconocimiento que de esa diversidad, con profundas consecuencias en todos los ámbitos, se había realizado en la Constitución de 1978 y en su desarrollo (Solozábal, 2004: 199). El nacionalismo no lo reconocía porque su modelo era otro cualitativamente distinto. Y, quizá lo más grave, se había dejado indefenso al Estado autonómico en la defensa de sus cualidades y de lo mucho que había aportado al reconocimiento de la diversidad territorial.

Más cualquiera que sea la reflexión que se quiera realizar, lo que resultaba evidente es que si en 1992 y 1996, las Comunidades Autónomas del 143 pusieron encima de la mesa su reivindicación en clave homogeneizadora, ahora las Comunidades del 151 lo hacían reivindicando la singularidad inicial. Y esa singularidad no era cualquiera. Se afectaba al nervio de la propia definición del Estado. No sólo se reclamaba una explicitación de aquello que en 1978 había quedado velado por la ambigüedad. Se daba un paso más y se declaraba como objetivo una transformación sustancial del Estado. La plurinacionalidad debía convertirse en el eje articulador del mismo.

Aunque las previsiones contenidas en la Declaración no tuvieron un particular recorrido inmediato, no podían hacerse esperar sus primeras traducciones jurídico políticas. La primera de ellas sería el comúnmente conocido como Plan Ibarretxe. La propuesta de Estatuto Político de la Comunidad de Euskadi, fue anunciada por el entonces Lehendakari Ibarretxe en el Pleno de Política General del Parlamento Vasco de septiembre de 2001; presentada en el Parlamento Vasco el 25 de octubre de 
2003 y aprobada por éste, el 30 de diciembre de 2004. Técnicamente, la Propuesta se planteaba como una reforma del Estatuto de Autonomía (Solozábal, 2006: 107). Sus fundamentos ideológicos y características, iban, sin embargo, bastante más allá de lo que pudiera calificarse como una reforma del Estatuto de Autonomía. El presupuesto político que sostenía toda la arquitectura del Plan era que el pueblo vasco era un pueblo de Europa con identidad propia. La consecuencia natural de esa afirmación era que tenía derecho a decidir libremente su futuro político, es decir la afirmación del derecho a la autodeterminación. Junto a ello, el texto contenía una serie de disposiciones de hondo calado político.

La propuesta del Gobierno de Ibarretxe dejaba sobre la mesa una lectura diferente del modelo territorial. El fracaso del texto no podía ocultar ni la inquietud política que dominaba a las formaciones nacionalistas ni el hecho de que la reforma de los Estatutos, en uno o en otro sentido, emergía como vía para dar satisfacción a esas inquietudes. Era claro que, frente a lo que algunos pensaban, la resolución del conflicto planteado por el Plan Ibarretxe, no cerraba el debate nacionalista sobre el Estado autonómico. En paralelo a su debate, en Cataluña habían comenzado los trabajos para preparar una reforma del Estatuto de Autonomía. Reforma que recibió el impulso político necesario con el acceso al Gobierno de España, en marzo de 2004, de José Luis Rodríguez Zapatero.

La necesidad no ya de una reforma del Estatuto de Autonomía sino de la aprobación de uno nuevo que modificase incluso los términos de la presencia de Cataluña en el Estado autonómico, se adueñó de la agenda política catalana, aunque distaba de ser claro que para la mayoría de los catalanes fuese una prioridad incrementar los niveles de autogobierno ${ }^{6}$. Finalmente, el texto que el Parlamento de Cataluña remitiría al Congreso de los Diputados, si bien carecía de la tosquedad jurídica del Plan Ibarretxe, no se alejaba, en algunas de sus afirmaciones, de los presupuestos jurídicos y políticos del mismo.

Por todos es conocido lo que sucedió después. A diferencia de lo sucedido en el País Vasco, los avatares del Estatuto de Autonomía de Cataluña se concatenerán con una muy grave crisis institucional. En todo caso, a efectos del discurso que se sigue en estas páginas, lo relevante es mostrar la conexión de estos dos textos con el contenido de la Declaración de Barcelona y, por ende, con la concepción netamente asimétrica que del Estado tenían las formaciones nacionalistas vascas y catalanas (De Miguel, J: 2016: 65) ${ }^{7}$.

6 Antes al contrario, según encuesta del CIS, a comienzos del 2003 sólo preocupaba al 3,9\% de los catalanes, frente a un $54,4 \%$ que tenían al desempleo como principal preocupación. Durante el verano de 2005, mientras se estaba debatiendo el Estatuto, el 14\% de los catalanes consideraba que éste era el primer problema de Cataluña.

${ }^{7}$ La ausencia de Galicia sólo ratifica la tesis expuesta al inicio de estas páginas. Esa ausencia era coherente con el carácter minoritario del voto nacionalista en esta Comunidad. De hecho, el electorado gallego, lejos de castigar al Partido Popular por bloquear la aprobación de un nuevo Estatuto de Autonomía, le premió con la recuperación del poder. 


\section{B. Los Estatutos de autonomía de segunda generación y la apariencia de emulación}

La aprobación del Estatuto de Autonomía y los debates consiguientes abrieron una nueva etapa del Estado autonómico. Una etapa marcada por la aprobación en distintas Comunidades de nuevos Estatutos, los denominados Estatutos de segunda generación. Las Comunidades Autónomas apostaban por dar por cerrada una etapa del Estado autonómico y aprobaban un nuevo Estatuto como norma fundacional de la nueva etapa (Solozábal, 2007; Montilla, 2016: 59-64).

Andalucía, Comunidad Valenciana, Aragón, Islas Baleares, y Castilla y León, protagonizaron la primera etapa de este proceso. En un segundo momento se sumarían, Extremadura y Navarra. Lo primero que resulta pertinente subrayar es que el contenido de estos textos difiere sustancialmente entre ellos (Tudela, 2016: 179). Junto a una evidente voluntad de aggiornamiento del texto estatutario, incorporando al mismo contenidos y realidades extra estatutarias pero de naturaleza materialmente estatutaria, estos documentos perseguían dar respuesta a determinadas circunstancias particulares como la organización territorial en Baleares o la gestión del agua en Aragón. Pero, sobre todo, diferirán en su vocación política e ideológica. Así, por ejemplo, en Extremadura no se procedió a la aprobación de un nuevo texto, sino una reforma. Aunque materialmente pueda hablarse de un nuevo Estatuto, el legislador extremeño quiso reivindicar la esencia del Estado autonómico y del que había sido su desarrollo hasta entonces. De esta manera, se enfrentaba sin disimulo con la concepción existente en otros textos (Sánchez Amor, 2011: 25-91).

Desde luego, la diferencia más notable la marca el Estatuto de Autonomía de Andalucía. De hecho, es el único texto que admite como término de referencia el Estatuto de Autonomía de Cataluña. Con reiteración se indica que los dos textos son sustancialmente idénticos. Pero las notables similitudes entre los textos de Andalucía y Cataluña, no significa equivalencia. Como ya he tenido ocasión de subrayar, tanto desde una perspectiva ideológica, esencial para interpretar los preceptos dudosos como desde ciertos aspectos del contenido material, ambos textos muestran significativas diferencias (Tudela, 2016: 170-177).

Unas diferencias que, más allá de su relación con sus avatares posteriores, son relevantes para la cuestión examinada en estas páginas. El tiempo de los Estatutos de Autonomía de segunda generación no es un tiempo de emulación, sino de acomodo voluntario de la diferencia. Es decir, por vez primera, la concepción asimétrica del Estado no se impone desde arriba. Por el contrario, es el fruto de la propia concepción que las distintas Comunidades Autónomas tienen de su relación con el autogobierno (Montilla, 2016: 211). De alguna manera, el estirón que representaba el texto catalán, suponía traspasar determinadas barreras que ya escapaban con claridad a la voluntad del resto. Porque, y ésta es la cuestión esencial, no se trataba ya de mayores o menores dosis de poder traducidas en unas u otras competencias. Se trataba de la visión ideológica que sobre el conjunto del Estado tenían una u otra Comunidad. Es decir, se trataba de la visión que en relación con la unidad y con la nación española podían 
tener cada una de las Comunidades. Hay que recordar que, por vez primera, los textos remitidos por los Parlamentos autonómicos prácticamente no llegaron a ser modificados en las Cortes Generales. Más. Incluso se procedió a extender el procedimiento de reforma paccionado con la presencia en el Congreso de una delegación del correspondiente Parlamento autonómico. Desde esta perspectiva, puede afirmarse que el resultado es una asimetría voluntaria.

Una afirmación que se refuerza con un dato que en demasiadas ocasiones pasa desapercibido. Lo sucedido en aquellas Comunidades Autónomas que no llegaron a ver aprobado un nuevo texto. Se han citado ocho territorios. Por ende, hay nueve que no procedieron a modificar su Estatuto. De nuevo, tampoco es posible realizar una afirmación omnicomprensiva. De esos nueve, dos remitieron sendos y ambiciosos proyectos a las Cortes Generales. Canarias y Castilla La Mancha. Los dos acabaron siendo retirados por cuestiones particularmente polémicas sobre las que no se llegó a acuerdo. El régimen electoral en el caso de las Islas Canarias, el trasvase Tajo Segura, en relación con el texto de Castilla La Mancha. Junto a ello, en Galicia no fue posible alcanzar la mayoría parlamentaria de los dos tercios. La falta de acuerdo con el PP lo impidió (lo que no obstaría a que en las siguientes elecciones autonómicas, el PP obtuviese mayoría absoluta). Si se recuerda el intento del Plan Ibarretxe, se concluirá que en otras cinco Comunidades ni siquiera se intentó la modificación del Estatuto. Son Madrid, Murcia, La Rioja, Cantabria y Asturias. Al menos, con una mínima determinación, ya que en alguna de esas Comunidades si se iniciaron algunos trabajos preparatorios.

Ha sido habitual señalar que la reacción de las restantes Comunidades después de que Cataluña iniciase el proceso de reforma de su Estatuto, fue una nueva y palmaria demostración de la fuerza del principio de emulación, condicionando la evolución del Estado en clave homogeneizadora. Una lectura que a la luz de los datos derivados de lo sucedido resulta imposible. Sucedió lo contrario. Si algo demuestra el tiempo de los Estatutos de Autonomía de segunda generación, es que la emulación había llegado al límite. De forma contundente, el modelo homogéneo de Estado alcanzado con el proceso consecuente a la reforma de los Estatutos de Aragón y Canarias de 1996, había desaparecido, sustituido por un modelo asimétrico, más coherente con el diseño dibujado en la Constitución. Algo que había sucedido por la voluntad de los distintos territorios. En sus respectivas reformas, todas las Comunidades habían explicitado que su modelo de estar en el Estado era diferente al de Cataluña (Fossas, E., 2007: 102). Dando un significativo rodeo, el tiempo daba la razón al constituyente y al modelo de Estado dibujado en el artículo 2. Es posible afirmar que en puridad, las diferencias consecuencia de las reformas estatutarias no pueden calificarse de asimetría. No tendrían la cualidad necesaria para ello (Castella, 2016: 76). Pero creo que es una visión demasiado estricta. Las diferencias entre los Estatutos de Cataluña y Andalucía y el resto de los reformados o aprobados, eran relevantes. Por ejemplo, afectaban a cuestiones como el blindaje competencial o la financiación. También lo eran las declaraciones programáticas e ideológicas contenidas en los preámbulos y 
primeros artículos. Y, además, no puede soslayarse la existencia de un número relevante de Estatutos que permanecían sin reformar y frente a los cuales se multiplicaban las diferencias. Diferencias todas ellas surgidas desde la voluntad política. Así, creo que sí es posible defender que, con la intensidad que se considere, el resultado del proceso de los denominados Estatutos de segunda generación fue el regreso al diseño asimétrico del constituyente. Un diseño, en todo caso, fruto de la voluntad de cada territorio y no resultado de un gran acuerdo político nacional.

La dinámica de la relación entre simetría y asimetría había atravesado el devenir del Estado autonómico y había sido decisiva en el dibujo final de un modelo de Estado. Sólo desde esa dialéctica era posible entender los perfiles del denominado Estado autonómico. En una nueva vuelta de tuerca de esa dinámica dialéctica, la asimetría, con un ejercicio contundente, se había mostrado más poderosa. El diseño final del Estado autonómico parecía inclinarse definitivamente hacia la asimetría, negando la idea de que la igualdad de las diferentes Comunidades Autónomas era esencial a su diseño (Castella, 2016: 80). Así se desprendía del texto de los diferentes Estatutos y así parecía ser la voluntad de los propios actores políticos. Junto a ello, además, siempre habría que recordar la permanencia de la más relevante y expresiva asimetría, la que representaba el régimen foral del País Vasco y Navarra, con el añadido de la interpretación que se había realizado de la misma.

\section{UN BALANCE QUE SE PROYECTA AL FUTURO}

Antes de adentrarse en la reflexión final, y al objeto de poseer una visión más completa de los elementos que se desenvuelven alrededor de la dialéctica estudiada, es preciso realizar una reflexión adicional. La lectura constitucional desde los textos normativos deja necesariamente al margen ciertas circunstancias relevantes a la hora de tener una comprensión global de la dialéctica estudiada. Me refiero a la distinta posición informal que los distintos sujetos territoriales poseen en las dinámicas propias de un Estado descentralizado. La posición política de las distintas Comunidades no ha sido nunca la misma. Por una parte, País Vasco y Navarra no sólo han mantenido las diferencias derivadas de la dicción constitucional, sino que en el juego de las dinámicas políticas, las han acrecentado sustancialmente. Por un lado, en relación con el resultante de su singular sistema de financiación. Por otro, como consecuencia de la cada vez más amplia interpretación otorgada por el Tribunal Constitucional a la institución de los Derechos históricos (Razquín, 1991: 79-90).

Simultáneamente, el peso político de Cataluña se ha hecho valer de manera muy diversa y contundente, hasta el extremo de que se puede llegar a realizar una teoría de su posición asimétrica desde la práctica constitucional. Me limito a citar dos circunstancias. Por un lado, la especial posición que a esta Comunidad le ha otorgado la presencia en las Cortes Generales de Grupos Parlamentarios nacionalistas de manera constante. Por otro, la muy singular posición que se le reconoció oficiosamente en 
todos los procesos de reforma del sistema de financiación. Como no podía ser de otra manera, las dinámicas del poder siempre han tenido en consideración las características de Cataluña en el conjunto del Estado (Saénz Royo, 2014: 54).

Si a ello se une la asimetría normativa resultante de la aprobación de los denominados Estatutos de segunda generación, que se sumaba a la ya reconocida para País Vasco y Navarra, podrá concluirse que frente a la imagen generalmente extendida, la dialéctica aquí estudiada acabó decantándose del lado de la asimetría. Es decir, el modelo diseñado por el constituyente no fue modificado por el devenir constitucional. Es cierto que la Constitución posibilitaba una construcción territorial finalmente simétrica. Y es cierto que hubo un tiempo, breve en el conjunto del desarrollo constitucional (1999-2006), que, y siempre con la excepción de País Vasco y Navarra, la balanza se decantó del lado de la simetría. Pero se acabó imponiendo el criterio del constituyente, demostrando, por lo demás, que era más acorde con la realidad política y sociológica de los distintos territorios. El diseño asimétrico era fiel a una distinta manera de relacionarse con el autogobierno del País Vasco y Cataluña. La fuerza ideológica que sostenía la premisa del reconocimiento de la singularidad de País Vasco y Cataluña, acababa imponiéndose incluso frente a un principio de emulación que había demostrado un notable vigor. España había devenido en un Estado cuasi federal como respuesta natural a la existencia de identidades duales y la asimetría era la fórmula natural a esta circunstancia (Moreno, 2009: 127).

Fue ese sustrato el que provocó la decisión de aprobación de un nuevo Estatuto de Autonomía en Cataluña en el año 2005. Una decisión que, como se ha visto, tenía raíces en el descontento ya reflejado en la Declaración de Barcelona de 1998. Las Comunidades del artículo 143 habían encontrado su acomodo en el desarrollo del modelo constitucional de organización territorial del poder. Ahora correspondía esa reacomodación a las Comunidades del 151. Y muy en particular a Cataluña, que no disponía de la vía de escape de la singularidad del régimen foral. El Estatuto de 2006 debía cumplir esa función. Corregido primero por las Cortes Generales y después por el Tribunal Constitucional, el resultado fue rechazado por el nacionalismo catalán. Desde esta premisa, las fuerzas políticas nacionalistas pasaron a entender que la singularidad de Cataluña no podía ser reconocida dentro del Estado, por lo que sólo cabía la independencia.

Se ha escrito, y se escribe, que el Estatuto fue una gran oportunidad perdida. Que si el pronunciamiento del Tribunal Constitucional hubiese sido otro, hubiésemos podido disfrutar de otros veinte años de conllevanza orteguiana. Personalmente soy escéptico respecto de esta tesis. El proyecto de Estatuto aprobado por el Parlamento de Cataluña, el texto que reflejaba la voluntad mínima de las fuerzas políticas catalanas, era un texto de vocación nítidamente confederal, que contradecía abiertamente la Constitución en cuestiones fundamentales, tal y como entendió el propio Congreso de los Diputados. Las modificaciones introducidas por éste, hay que recordarlo, supusieron la pérdida del apoyo de Esquerra Republicana al nuevo texto. Desde esta 
premisa, parece muy aventurado hacer predicciones sobre qué hubiese podido suceder sin pronunciamiento del Tribunal Constitucional o con otro en sentido diferente.

En todo caso, el nacionalismo catalán dejó de instalarse en la dialéctica estudiada para tener la independencia como exclusivo objetivo político (Enoch Alberti, 2016: 257-265). Se han buscado muchas explicaciones, incluso responsabilidades a esta deriva. No son objeto de estas páginas. Sí lo es reflexionar sobre el hecho de por qué el nacionalismo mostró durante años su conformidad con un diseño y posición en el Estado que singularizaba a Cataluña y si la apertura del camino hacia la independencia no tiene que ver con el hecho de que, a la postre, las fuerzas políticas españolas no han sabido desarrollar de forma acertada la asimetría que sí fue correctamente percibida y establecida por el constituyente.

El constituyente no pudo tomar algunas decisiones. Concretar la traducción de la ideología de la asimetría no era tarea sencilla. Además, algunas decisiones constitucionales podían jugar un rol contradictorio en el desarrollo de la Constitución. Si la opción por un modelo que se acercaba a lo que tradicionalmente se definía como un Estado regional favorecía la idea de asimetría, el principio dispositivo, al menos en un primer momento, la contradecía. Tensiones contradictorias que pueden explicarse por la casi inevitable ambigüedad en la que en aspectos esenciales tuvo que desenvolverse el constituyente. Lo que resulta más criticable es que el desarrollo de esos principios constitucionales lejos de estar guiado por la convicción y conformidad con una idea previa, se dejase a la más limitada de las coyunturas políticas. La organización territorial era un tema central de la construcción constitucional de la España moderna. Una cuestión esencial en si misma, pero que en España adquiría la condición de nuclear por el desafío que representaba la acomodación de los nacionalismos vasco y catalán, fue desdeñada y abandonada a sus propias dinámicas sin que una visión de conjunto del Estado la cubriese. Una visión técnica e ideológica. De organización de la complejidad derivada de la existencia de numerosos núcleos de poder político y desde el reto ideológico que suponía la necesidad de integrar en un proyecto nacional la convivencia de una pluralidad de realidades con vocación nacional. Ello explica que se frivolizase el significado y valor de una voz como nacionalidad o que no se reparase en las corrientes que subyacían a un texto como la Declaración de Barcelona. O que primero el Presidente Aznar y después el Presidente Zapatero obviasen la transcendencia de este tema y la necesidad de pactos entre las dos grandes formaciones políticas nacionales. Es preciso reconocer que en el desarrollo de la organización territorial, ha sobrado frivolidad e improvisación y ha faltado sentido de Estado.

Por supuesto, en la hora de explicar el fracaso del proyecto constitucional en relación con la integración, el debe no puede adjudicarse únicamente a las fuerzas políticas nacionales. El nacionalismo ha sido profundamente desleal con el proyecto común. Si bien es cierto que en ocasiones, algunas relevantes, las fuerzas políticas nacionalistas actuaron de conformidad con la denominada razón de Estado, más lo es que siempre fueron leales a un proyecto político nacional excluyente con la integra- 
ción y la pertenencia al todo. Un proyecto que se construyó en la dialéctica amigo/ enemigo frente a España. Y sin esa lealtad es innegable que resulta difícil construir cualquier proyecto colectivo. Ahora bien, ello no resta valor a la crítica al comportamiento de los principales actores de la política nacional durante estos años. No desconocían lo que era visible para todos. Por ello mismo, su frivolidad y falta de rigor resulta más grave. No sólo es reprochable que no se buscasen antídotos a las pulsiones de fondo, algunas explícitas y otras no, que llegaban desde el nacionalismo. También lo es la falta de inteligencia para poner en valor lo que el Estado autonómico representaba para todas las Comunidades Autónomas y, muy especialmente, para País Vasco y Cataluña. Incluyendo los relevantes rasgos informales de su funcionamiento asimétrico. Aun hoy es posible escuchar numerosas voces desde los dos territorios, y muy especialmente de Cataluña, reprochando al Estado, a Madrid, su incapacidad de aceptación de la diversidad. Como si nada hubiese sucedido desde 1975, como si Cataluña no fuese la realidad política que es. Ello es lamentable. Pero también lo es que no se haya sido capaz de articular el discurso político e ideológico que pusiese en valor todo lo que se niega.

Hoy puede decirse que desde la asimetría se ha encontrado una respuesta esencialmente satisfactoria al nacionalismo vasco. Si se enfrenta la voz asimetría a Cataluña, la respuesta es paradójica. Por una parte, Cataluña alcanza con el Estatuto de 2006 una posición asimétrica desde la norma. Y mantiene una cualidad de hecho en el conjunto del Estado, enriquecida por numerosas expresiones informales de asimetría. Por otra, el nacionalismo catalán entiende todo ello como insuficiente y, dando un salto notable, alcanza la conclusión de que la singularidad que Cataluña merece y necesita no va a ser nunca posible en el conjunto del Estado. Por tanto, la independencia es el único objetivo plausible. Así las cosas, la pregunta es inevitable ¿Cuál puede ser el rol de la dialéctica examinada en el futuro ya inmediato de la organización territorial de España y, más en concreto, de la integración de Cataluña? Más ¿Es todavía posible pensar que el juego ordinario de una dialéctica simetría/asimetría puede contribuir a encontrar una salida al presente de la situación territorial española? No hay una respuesta posible. No la da el derecho constitucional y no la da la ciencia política. Pero creo que no es arriesgado aventurar que, en todo caso, el diseño territorial que debe buscar esa salida, habrá de estar inspirado en las oportunidades que la asimetría concede al Derecho. Tal y como sucedió en 1978.

La dialéctica simetría/asimetría no sólo explica en buena parte la evolución del modelo de organización territorial diseñado por el constituyente. También, como se ha intentado demostrar, caracteriza y singulariza el modelo territorial representado por el llamado Estado autonómico. Más allá del pasado, o de un presente que tiene vocación de pasado, hoy emerge como el instrumento técnico y el reducto ideológico para la reconstrucción de la organización territorial del poder. Algo que sólo podrá realizarse de forma satisfactoria si se olvida cualquier posible asociación entre asimetría y privilegio y si se construye desde una concepción profunda de España como Estado y como Nación. Porque, en cualquier caso, no puede olvidarse que ningún 
Estado admite dosis de asimetría que, valga la redundancia, sean incompatibles con el significado ideológico, político y social de la pertenencia a un mismo Estado (Dion, 1999: 197). Desde todas estas premisas, en la actualidad, el juego de la asimetría debe asociarse desde el primer momento con una idea de flexibilidad que adquiere particular potencia en el conjunto del federalismo contemporáneo.

\section{BIBLIOGRAFÍA}

AJA, E. (2014), Estado autonómico y reforma federal, Madrid, Alianza AJA, E. y Viver, C. (2003), Valoración de 25 años de autonomía, REDC 69, 69-113. Alberti Rovira, E. (2016), La reforma constitucional y el futuro del Estado autonómico. En especial, el problema planteado en Cataluña en Tudela, J. y Garrido, C. (coords)., Actas del XIII Congreso de constitucionalistas de España La organización territorial del Estado, hoy. Valencia, Tirant lo Blanch.

Alli Aranguren, J.C. (2009), La fórmula del Estado de las autonomías como transición al federalismo asimétrico en Arrieta, J. y Astigarraga, J. (Eds), Conciliar la diversidad. Pasado y presente de la vertebración de España Bilbao, Fundación Ernest Lluch-Universidad del País Vasco.

Balaguer Callejón, F. (1992), Fuentes del Derecho Voluntad. II, Madrid, Tecnos.

Blanco Valdés, R. (2012), Los rostros del federalismo, Madrid, Alianza.

- El laberinto territorial español, Madrid, Alianza.

Carreras De, F. (2014), Prólogo en Tajadura, J. y De Miguel Bárcena, J. (Eds) Federalismos del Siglo XXI, Madrird, CEPC.

Castella, J.M. (2016), Estado autonómico ¿Asimétrico?, Cuadernos de Alzate 48-49, 71-92.

Corcuera Atienza, F.J. (1985), Notas sobre el debate de los derechos históricos de los territorios forales, REP 46-47, 55-90.

- La distinción constitucional entre nacionalidades y regiones en el décimoquinto aniversario de la Constitución española, Documentación Administrativa 232-233, 14-31.

Demarchi, G. (2017), La Segunda República y su(s) territorio(s): Los múltiples actores del Estado integral en Gordillo, L; Martín, S.; y Vázquez Alonso, V.J. (Dirs), Constitución de 1931: estudios jurídicos sobre el momento republicano español, Madrid, Marcial Pons

Dion, S. (1999), El federalismo fuertemente asimétrico: improbable e indeseable en Fossas Espadaler, E. y Requejo, F. (Eds.) Asimetría federal y Estado Asimetría federal y Estado plurinacional, Madrid, Trotta.

Fossas Espadaler, E. (1999), Asimetría y plurinacionalidad en el Estado autonómico en Fossas Espadaler, E. y Requejo, F. (Eds.) Asimetría federal y Estado Asimetría federal y Estado plurinacional, Madrid, Trotta.

- (2007), El principio dispositivo en el Estado autonómico, Madrid, Marcial Pons. 
Fossas Espadaler, E. y Requejo, F. (Eds.) (1999), Asimetría federal y Estado Asimetría federal y Estado plurinacional, Madrid, Trotta.

GAGNON, A-G. (2013), Época de incertidumbres. Ensayo sobre el federalismo y la diversidad nacional, Valencia, Tirant lo Blanch.

Guerra Sesma, D. (Ed.) (2016), El pensamiento territorial de la Segunda República española, Sevilla, Athenaica.

LAPORTA, F.J. (2006), Los derechos históricos en la Constitución: algunos problemas teóricos en Los derechos históricos en la Constitución, Madrid, CEPC

López Aguilar, J.F. (1997), Constitución, autonomía y hecho diferencial. El Estado autonómico y el hecho diferencial constitucionalmente relevante, Cuadernos de Derecho Público 2, 25-74.

Miguel Bárcena De, J. (2016), De nuevo, el federalismo asimétrico, Cuadernos de Alzate 48-49, 59-70.

Montilla Martos, J.A. (2016), Reforma federal y Estatutos de segunda generación, Pamplona, Thomson Reuters-Aranzadi.

Moreno, L. (2009), La federalización de la España plural, REAF 8.

MuÑoz Machado, S. (1992), Los pactos autonómicos de 1992: la ampliación de competencias y la reforma de los Estatutos, RAP 128, 85-105.

- (2007), Derecho público de las Comunidades Autónomas, Madrid, Iustel.

- (2014), Cataluña y las demás Españas, Barcelona, Crítica.

Ortego Gil, P. (2008), Comentario al artículo 148.2 de la Constitución en Comentarios a la Constitución española. XXX aniversario, Madrid, Fundación Wolters Kluwer, 2256-2263.

RAZQUín LiZARraga, M. (1991), Un hito en la jurisprudencia constitucional sobre los derechos históricos: la Sentencia 140/1990, de 20 de noviembre, Revista Jurídica de Navarra 11, 79-90.

Requejo, F. (2001), Political liberalism in multinational states: The legitimacy of plural and Aasymetric Federalism en Gagnon, A. y Tully, J., Multinacional Democracies, Cambridge, Cambridge University Press.

Ruiz Robledo, A. (1986), La Comunidad Autónoma de Andalucía, Granada, Universidad de Granada.

SAÉNZ Royo, E. (2014), Desmontando mitos sobre el Estado autonómico, Madrid, Marcial Pons.

SÁNCHEZ Amor, I. (2011), La reforma del Estatuto de Autonomía de Extremadura de 2010. Antecedentes y marco político en El nuevo Estatuto de Extremadura, Madrid, Fundación Alternativas.

SARmiento Méndez, X.A. (2003), O Estatuto de Galicia. 20 anos de parlamento e xustiza constitucionais, Vigo, Xerais.

Solozábal Echavarría, J.J. (2004), Nación y Constitución. Soberanía y autonomía en la forma política española, Madrid, Biblioteca Nueva.

- (2006), Tiempo de reformas. El Estado autonómico en cuestión, Madrid, Biblioteca Nueva. 
- (2008), Comentario al artículo segundo de la Constitución en Comentarios a la Constitución española. XXX aniversario, Madrid, Fundación Wolters Kluwer, 53-63.

- (20 I 4), Una propuesta de cambio federal en Solozábal Echavarría, J.J. (Dr.), La reforma federal. España y sus siete espejos, Madrid, Biblioteca Nueva.

Tajadura, J. y De Miguel Bárcena, J. (2014), El federalismo en la era de la globalización en Tajadura, J. y De Miguel Bárcena, J. (Eds.) Federalismos del Siglo XXI, Madrid, CEPC.

Tornos, J. (2015), De Escocia a Cataluña. Referéndum y reforma constitucional, Madrid, Iustel.

Trujillo, G. (2005), El federalismo asimétrico en la España del Siglo XXI: reflexiones sobre la reforma del Estado desde la reforma constitucional del Senado en Aguiar de Luque, L (Coord.), Constitución, Estado de las autonomías y justicia constitucional (libro bomenaje al profesor Gumersindo Trujillo), Tirant lo Blanch, 35-54.

Tudela Aranda, J. (2016), El fracasado éxito del Estado autonómico. Una historia española, Madrid, Marcial Pons.

Unzueta, M. (1999), La Declaración de Barcelona, El País 28-9-1998 disponible en https://elpais.com/diario/1998/09/28/opinion/906933604_850215.html

VV.AA. (1993) El Estado autonómico, hoy. Documentación Administrativa 232-233.

Watts, R.L., (2006), Sistemas federales comparados, Madrid, Marcial Pons.

Title:

The Asymmetry, no recognised differences, as a distinguishing feature of the State of Autonomies

Table of contents:

1. The debate on symmetry as the defining element of the State of Autonomies. 2. The constitutional basis of the debate. a. Political asymmetries. b. Recognised differences (hechos diferenciales). 3. Frustration, rebellion and emulation. 4. Nationality is everything and the need to go back to the origins. a. The Barcelona Declaration and its reflections on the Statute. $b$. The statutes of autonomy of the second-generation and the appearance of emulation. 5. A balance of what the future looks like

\section{Resumen:}

La categorización del Estado autonómico se ha desenvuelto desde su adscripción al Estado regional en sus inicios, a su consideración como uno de los rostros del federalismo en los últimos años. En cualquier caso, una de 
las características que ha sido subrayada reiteradamente como nota distintiva del mismo, es el principio de emulación. De acuerdo con el cual, la voluntad de igualación de los distintos territorios más el potencial técnico del principio dispositivo, daría como resultado un modelo de organización territorial caracterizado por la homogeneidad. En estas páginas se pretende demostrar que, por el contrario, la Constitución y la evolución del Estado autonómico demuestran que la verdadera nota distintiva del mismo es la asimetría. La asimetría entendida como la voluntad de singularización constitucional de algunos territorios y por la respuesta que esa voluntad ha tenido a lo largo del tiempo. Si bien hubo un tiempo en el que la fuerza del principio de emulación dio como resultado un Estado parcialmente simétrico, la posterior evolución demostró las profundas raíces de la asimetría como principio ideológico del modelo. Haber obviado esta dimensión del Estado autonómico se encuentra entre las razones de su fracaso como proyecto de integración.

\begin{abstract}
:
The definition of the Spanish State of Autonomies has been changed over the past decades. While the State of Autonomies has been classified in its beginnings as a regional state, in recent years the model developed features similar to a federal country. Notwithstanding, one of the characteristics that has been frequently underlined as a distinguishing feature of the State of Autonomies is the principle of emulation. Following this principle, the trend to equalize the different territories, in addition to the potential of the "principio dispositivo», according to which all powers that have not been reserved to the central government could be assumed by the Autonomous Communities, would lead to a model of territorial organization characterized by homogeneity. In this text we will demonstrate that, on the contrary, the Constitution and the evolution of the State of Autonomies show that the distinctive feature of the State of Autonomies has been asymmetry. In this context, we understand asymmetry as the desire for a constitutionally guaranteed distinction of some territories and the reactions this constitutional asymmetry had over time. Although during a certain period the strength of the emulation principle lead to a partially symmetrical state, the successive evolution of the State of Autonomies demonstrated the deep roots of asymmetry as the ideological principle of the model. The fact that this feature has been underestimated can be considered as one of the reasons for the failure of the State of Autonomies as an integration project.
\end{abstract}

Palabras clave:

Autonomía, Asimetría, Federalismo, Diversidad

Key words:

Autonomy, Asymmetry, Federalism, Diversity 